\title{
sciendo
}

\section{Digitalization of Coworking Space Services}

\author{
Enikő MÁTYUS \\ Bucharest University of Economic Studies, Bucharest, Romania \\ matyuseniko@gmail.com
}

\begin{abstract}
Coworking spaces are actors of the entrepreneurial ecosystem with strong social aspect and recognized impact regarding start-up communities. These establishments became frontrunners of increasing work productivity for people working from distance as well. They also make part of the businesses which are directly affected by the pandemic caused by Covid-19 virus. The paper attempts to define a digitalization opportunity of coworking spaces by adapting the business model to the current living conditions with special regards on the services they provide. Beside of identifying the key challenges and edges that the current situation brought, the paper assumes to provide insight information from the point of view of a hub operator and hub members, who decided to preserve their membership. The research includes a literature review of key concepts used within the analyses, followed by the definition of the methodology which covers a study case of a coworking space from a small city located in a developing country. A hybrid approach is included as solution in the paper supported by a business model proposal based on Canvas Business Model. The results of the research are reflecting the needs of a group of entrepreneurs representing micro enterprises, willing to participate in the creative process of business transformation and adaptation. The conclusion chapter summarizes the main findings in the form of recommendations and further alleged questions during the research.
\end{abstract}

Keywords: coworking spaces, covid-19, digital business model, digitalization, digital services, remote working.

\section{Introduction}

In the context of the Covid-19 pandemic coworking spaces operated by SMEs has been facing major challenges (Paunescu \& Matyus, 2020), once social distancing was imposed. Also, many countries entered into lockdown, condition which made almost impossible to run coworking offices, even with reduced capacity. The number of coworking spaces have increased in the last decade (Oswald \& Zhao, 2020), due to digital transformation of workflows (Grandini, 2015; Yu et. al, 2019).

Freelancers, teleworkers and digital nomads expressed their concrete needs for stimulative open spaces. Once these creative offices were launched, the concept acquired new missions and resulted a whole philosophy behind coworking, mentioned also as hubs. The intensive advances of digital technologies, implicitly the growth of digital businesses, created a demand for office facilities. Professionals in transit also have opted to work from these establishments and registered themselves as parts of that community even if they used the facility only for a very limited period. Contributing factor to the success of these spaces is the need of people for networking and to belong to a group with similar values. Coworking spaces are locations where people can rent for very short periods of time inclusively desks - working points. In general, these spaces are characterized by modern design and stimulative atmosphere addressed for start-ups dedicated to innovation (Amir, 2020). However, in the last few years remote workers and service companies in outsourcing are using coworking space facilities as well. Based on the dynamic of remote working (Choudhury, 2020), we can pronounce that coworking spaces are for everyone, even students are using them instead of noisy coffee houses. Beside of the design of the infrastructure and notoriety of the brand, 
the most important added value of these spaces are community building activities (Castilho \& Quandt, 2017) as workshops, professional events and informal activities.

The existing studies are mostly analysing the biggest coworking establishments, functioning mainly in international networks. Following the European measures concerning economic development of areas outside of metropolitan zones, the research focuses on solutions for early-stage start-up ecosystems and coworking initiatives which are operating in smaller towns. With the participation of such a coworking space members, the paper provides a hybrid approach - synergy of online and offline services of coworking space facilities. The conclusion chapter includes policy recommendation, strategic measure proposals and incurred issues for further research.

In the present paper we propose to analyse a small coworking space and its capacity to digitalize the operational processes and the services in order to engage the community even remotely. Coworking spaces has to be analysed as SMEs from the service sector, which are becoming more a business-to-business type of phenomena. As service providers they should be aware of the importance of adaptability in order to stay competitive (Păunescu \& Argatu, 2020) even if the essential processes are affected.

\section{Literature review}

As scholar Mina Akhavan (2021) presents in her comprehensive literature review on coworking spaces and marketspaces, published in January 2021, the phenomena of coworking concerned several researchers in the last few years.

Coworking spaces are approached as best practices for sharing economy in some of the scientific works (Waters-Lyncha and Potts, 2016; Bouncken et. al, 2020) - a global ambition for sustainable development. The scientific literature also discusses the positive impact of this kind of infrastructures on regional development (Maher, Tantawi, and Ragheb, 2020) and on innovation (Özbozkurt, 2019), with particular attention to the benefits of these facilities for digital business models (Bouncken, Kraus, and Martínez-Pérez, 2020).

However, we can observe a gap regarding scientific research on the digitalization of the coworking space business model itself. Digitalization of a business model aims to increase competitiveness within the company (Tresh \& Billinger, 2017) and can affect different elements of the business model: value proposition, delivery and communication channels, digital key resources or even activities. In these regards, many scholars differentiate digitalization from digitization. Digitization generally refers to the nature of the used data by the company guided by a software to proceed it (Ritter and Pederson, 2019). Digitalization is a tool for coworking spaces to innovate. Business Model Innovation (Tresh \& Billinger, 2017) becomes essential in the light of the current situation concerning the fact that people are encouraged to work from home, which raises the issue of the validity of the traditional coworking space business model (BerbegalMirabent, 2021). The spread of Covid-19 virus introduced the biggest remote-working exercise worldwide in the human history. According to Forbes (2020), the pandemic increased the importance of coworking spaces because many corporates decentralized the workplaces and remote workers have to operate from somewhere. Despite of this prevision, a survey conducted by Coworker platform (Coworker, 2020) with 15.000 members, shows that in more than $70 \%$ of the coworking spaces the number of visitors is in decline and many of the members suspended their memberships. The same study shows that $20 \%$ of the coworking spaces have been closed at the very beginning of the pandemic (Coworker, 2020). Due to the articles on the platform, the most common adaptation activities are: extra hygiene and disinfecting measures, single-person rental 
opportunities \& price reduction. On the other hand, all the entities had to cancel their community events, one of the core values of a coworking space, the element which differentiate it from an office with services. Some of the operators moved these events in online environment, but it still remains a question how the networking part can be handled in the virtual area.

In this given context, it is essential to analyse the concept of virtual incubators, which are approached as short-term intervention programs in the scientific literature, rather than virtual twins of a business incubator. The concept of "incubators without walls" (Hackett \& Dilts, 2004) appears in several policy recommendations especially because its capacity to support companies from disadvantaged areas and to enlarge the impact of the business support activity. A new concept is unfolding - Coworking space without walls - referring not to the open spaces but to digital services from coworking operators in order to preserve a certain number of members.

Taking into consideration the context induced by the Covid-19 pandemic and the fact that some of the governments recently published resilience and recovery strategies for national economies, the topic is highly relevant and low researched.

To the best of the author's knowledge, there is a limited number of scientific articles approaching specifically the effects off the pandemic on coworking space operators and discussing possible recovery scenarios for this specific industry. We found only 2 matching scientific articles investigating specifically coworking spaces in the context of the pandemic, not just mentioning them as alternatives for workplaces in the present: : "The Effects of Covid-19 on Coworking Spaces: Patterns and Future Trends" written by Ceinar and Mariotti (2020) and "Coworking Spaces in Germany during the Covid-19 Crisis Utilized for Homeoffice and Homeschooling" (Gruenwald, 2021)Within the book "New workplaces: Location patterns, urban effects and development trajectories - a worldwide investigation", there is a 14-pages chapter dedicated to coworking spaces, including the results of a global survey addressed to coworking managers(Mariotti et al., 2021). The mentioned investigation highlights mostly the position of coworking operators working with strong start-up ecosystems, inclusively digital nomads.

The present research analyses one model in detail and the capacity of upcycling the existing value through digitalization. The theorization within this paper can help smaller initiatives to endure this challenging times. Dedicated, international coworking platforms and coworking business chains are publishing articles and surveys in order to support the players of the industry: Coworker.com, Wework.com, Coworkingeurope.net and others. Preserving the activity means, to engage the target group even when the space cannot be visited physically.

\section{Methodology}

The methodology that assisted in the undertaking of the research, implied qualitative analysis. Qualitative research was conducted by literature review findings, taking in consideration also surveys and studies of the biggest platforms of coworking spaces. On the other hand, there took place an online and face-to-face interviewing session with the coordinator company of the InnoHUB Coworking Space (www.innohub.center) from Sfântu Gheorghe, Romania and the 17 member companies of the hub. The questions of the interviews allowed to the contributors to express their personal opinions concerning the digitalization of the coworking services. The aim of the addressed questions was to understand the members motivation to preserve their contracts in the hub. On the other hand, they were asked to propose services they would use within the hub.

In order to define relevant proposals, we used the testimonials of coworking managers published by Coworker.com during 2020 about the measures they take in the current situation. 
The research questions are: How a business, based on human interactions, shared desks and events can survive? How the core value proposition of such a business, namely community, can be adapted to the present circumstances? In this paper we will detail possible actions, strategic measures and best practices that coworking spaces can implement in order to preserve their activities. For the holistic demonstration of the findings, we used Canvas Business Model developed by Osterwalder (Osterwalder et al., 2010).

\section{Results}

This paper is analysing coworking spaces in the light of the global pandemic and assumes to propose possible alternative and new services that operators may adapt. The proposals are based on a synergic approach of testimonials within "Survey: How Coworking Spaces are Navigating COVID-19" (Coworker, 2020) and of the interviews conducted at the InnoHUB Community, Romania.

In the case of InnoHub Coworking Space from Romania, the first and only hub of Covasna county, the most popular coworking facilities are affected: conference and meeting rooms, shared kitchen, chill corners, offline mentoring sessions, workshops, printing services and others. Typical packages in the case of small coworkings includes mostly offline facilities. InnoHub is managed by a local microenterprise and has the following packages of services:

Table 1. Service packages of InnoHub Coworking Space - Romania

\begin{tabular}{|l|l|l|l|}
\hline $\begin{array}{c}\text { Name of the } \\
\text { package }\end{array}$ & \multicolumn{1}{|c|}{ Drop-in } & \multicolumn{1}{c|}{ Part-time } \\
\hline $\begin{array}{l}\text { Services } \\
\text { included }\end{array}$ & $\begin{array}{l}\text { 1 day pass } \\
1 \text { coffee/tea and water }\end{array}$ & $\begin{array}{l}\text { Premium } \\
\text { 1 week pass } \\
\text { Printing up to 50 pages } \\
\text { Access to conference room } \\
\text { (1 hour) } \\
\text { Access to the meeting } \\
\text { room (1 hours) } \\
\text { Access to the ongoing } \\
\text { events }\end{array}$ & $\begin{array}{l}\text { Access to conference room } \\
\text { Printing up to 150 pages } \\
\text { (5 hours) }\end{array}$ \\
& $\begin{array}{l}\text { Access to the meeting room } \\
\text { (5 hours) } \\
\text { Access to all the ongoing events } \\
\text { Access to networking sessions } \\
\text { Mentoring and consultancy session } \\
\text { (financing opportunities) }\end{array}$ \\
\hline
\end{tabular}

Source: www.innohub.center.

The main changes within the coworking space due to the pandemic are the followings: the drop-in and part-time packages were cancelled; the hub was closed for new members in the period of March 2020 and January 2021.

According to the administrator company of the hub, from 20 contracts only 3 were cancelled, 2 at the beginning of the pandemic and 1 recently. The first 2 cases are directly connected to the current situation, as the activities of the start-ups were suspended by the government, and they did not find any alternatives to continue the company's activity and in 1 case the motivation is related to the development of the company - a marketing agency - who rented out a private office with its new collaborators.

From the 17 persons, 8 frequented the hub constantly since March 2020. The interviews conducted with the member companies expresses clearly that InnoHub succeeded to develop a strong and loyal community. We asked those 9 people why do they pay the rent even if they do not use the hub, and they gave us the following answers: they don't want to lose their place because 
they are aware of the demand on the market of such facilities and because they are expecting to "get back to normal" soon and not at least, because of the advantageous price/quality rate of the services. The participants also highlighted that they appreciate most the community nature of the hub, which helps them to engage new clients as the coworking space is located in a business incubator.

One of the key findings of this paper is that coworking space coordinators have to become mentors for their member businesses more than ever and to support their survival in the market. Most of the countries launched granting programs and financial support to the economic sector. In these circumstances, coworking space operators can assume the role of facilitators in order to help their members to access available grants. Facilitating the access to finance is a strategic measure that organizations can provide and requires small efforts. This service implicates knowledge and information transfer, and the channels have to be defined. As mentioned before, most of the operators moved their knowledge transferred activities in the online environment. These activities have open access in many cases, so what makes reasonable to a start-up to join the specific community and to pay membership fee? At the same time, several professional conferences are available or required small fees in order to be accessed. Based on the interviews, start-ups of InnoHub expressed their need for digital services and they proposed 13 different utilities: Online payments, To get administrative notifications, Funding opportunities (published by admin), Internal service demand/supply publication (collaboration between members), Brainstorming sessions with members, Centralized up-to-date information (financial, legal, other news), Initiation of new projects, Detailed member profiles, Communication with admins, Internal communication with other members, Online workshops and thematic events, Online mentoring. Meanwhile, the operator of InnoHub suggested a platform for the community combined with the ecosystem of the whole incubators. On the second stage, we asked the starters to prioritize the possible functionalities of the proposed platform.

The below chart expresses clearly, that after almost 1 year of social distancing and restrictions, the startupers of InnoHub community needs interactions and would appreciate a better facilitation of collaboration. What before happened within a networking event, as understanding better each other's activity and expertise, now a digital fingerprint is needed in order to support the start of a conversation.

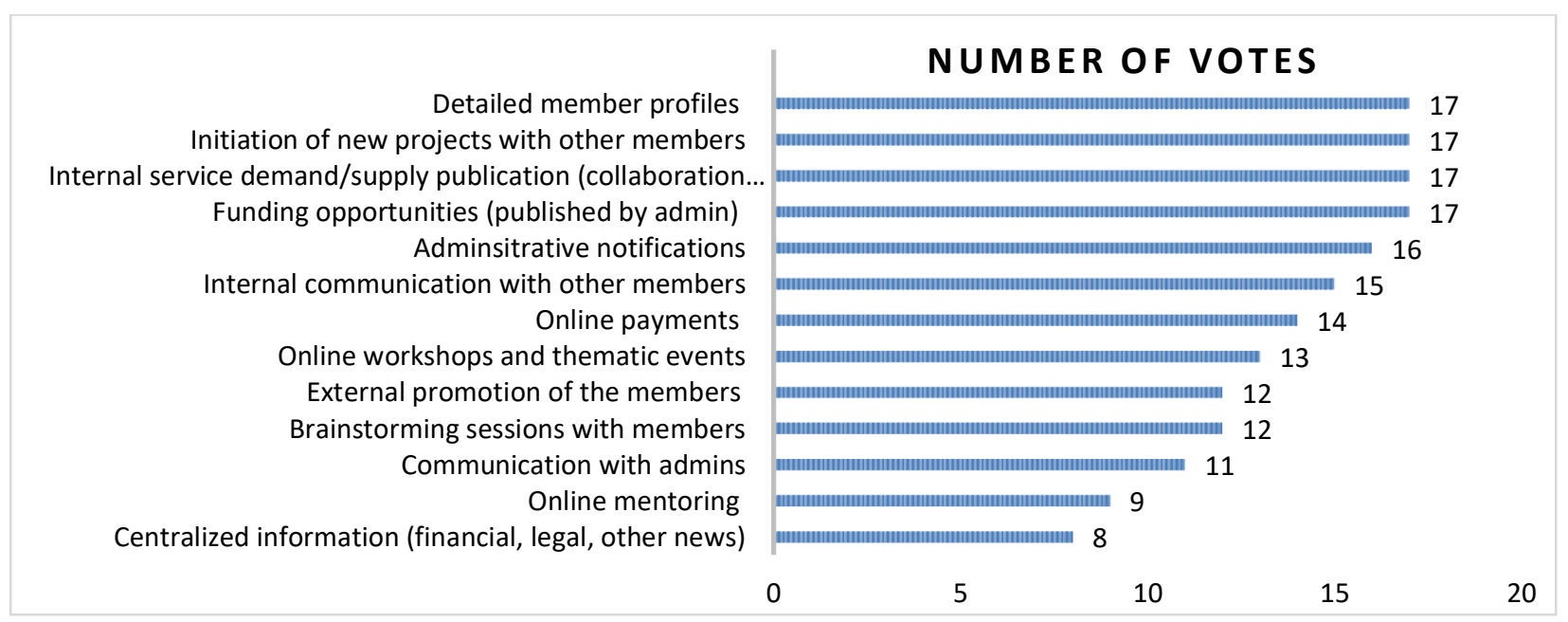

Figure 1. Prioritized digital services of InnoHub Coworking Space members

Source: Author's own research.

DOI: $10.2478 /$ picbe-2021-0100, pp. 1060-1068, ISSN 2558-9652 |

Proceedings of the $15^{\text {th }}$ International Conference on Business Excellence 2021 
At the beginning of the list, there are activities referring to development by collaboration and access to finance. In addition, we see the expectation for digitalized internal administrative activities. In this vein, more than half of the participants in the survey voted for online thematic events and workshops organized by the administration for them, highlighting topics as funding opportunities, tips and tricks for entrepreneurs, digital transformation, digital innovation hubs and internationalization. Some of the start-ups raised the issue of Global Sustainable Development Goals and Green Deal. At the same time, more than half of the testimonies express the interest to be promoted by the operator. Testimonies also show an interesting behavior, due to what information people tend to gain from the social media ( $76 \%$ of the participants). The key point of centralizing by the operator the actual information, which concerns the members would be the ensured reliability and authenticity of the information.

On the other hand, if coworking spaces are offering shared desks, shared working and relaxing spaces, in the digital area, these facilities could be incorporated in digital works surfaces. This would mean that operators are buying/renting popular software, platforms and applications to be further included in the service packages. Based on our survey, the most popular digital tools used by the 17 start-ups are: Software program for online meetings, Application for online scheduling, Online platform for presentation elaboration, Online platform for graphic design, Social Media Marketing Management platforms, Team management applications.

By analysing the mentioned softs, there is a free of charge version of each of them with limited features. Coworking operators could buy the full-access version of the most used software and to include in the package of the subscription for the period of the renting/membership contract. On the other hand, coworking spaces could provide cloud storage services for the members.

All the enumerated services are addressed more or less to long-term runners, because the number of transits coworkers is limited in this time. This out of wall services opens new horizon for coworking spaces in order to enlarge their ecosystems with talented people from other parts of the country.

Digitalizing the business model of a coworking space involves the transformation of all the component of a Business Model Canvas (Osterwalder et. al., 2010), starting from key partners. For instance, before the pandemic (The Business Model of Coworking, 2014) there was a common acceptance that one of the most important partners is the internet provider. Of course, this service remains essential, especially because we are treating hybrid solutions, but for members who are working from home and are still parts of the community, the internet service provider of the coworking space has no relevance anymore. But the application software program providers are getting in the highlight, concerning the digitalized business model of the coworking.

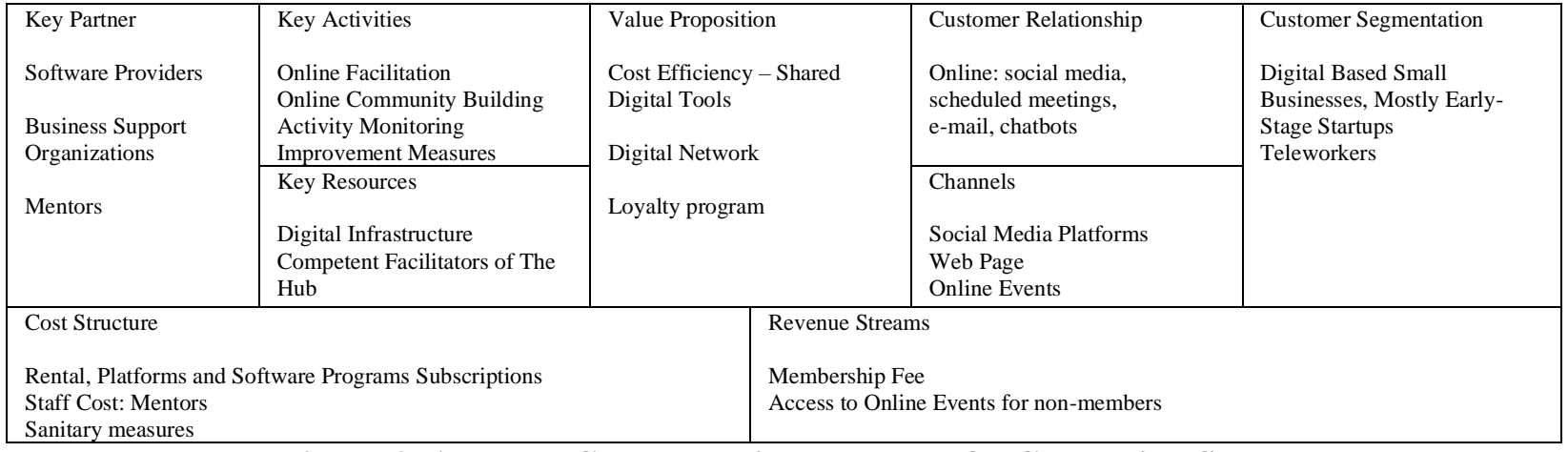

Figure 2. Adapted Canvas Business Model of a Coworking Space

Source: for template: Osterwalder et. al., 2010; for content: Author's own research. 
Digitalizing our business model does not mean the single fact that operators start to offer services using online platforms, but the digitalization of the management as well. This can mean the transformation of the following activities: working point/room reservation, membership subscription, entrance, reception, contract signing, etc. The aim is to transform these operations into a touchless one, with limited interaction between parties. Of course, this also required to implement online measures in order to keep the community character of the activity, by online welcome meeting, scheduled conversations to get to know the new members, etc.

PICBE | 1066

\section{Conclusion and discussions}

The expansion of the coworking space market was affected worldwide by the Covid-19 pandemic. However, the adaptation capability of the industry shows a flourishing future for a part of the actors. Beside of sanitary measures, coworking spaces moved knowledge sharing activities to online channels.

Digitalization of the operations can represent a solution for enhancing safety within these places. Similarly, to the tourism industry, coworkers has to assume personally the risks of using this facilities. Smaller coworking spaces should form consortiums and to provide jointly knowledge content and mentoring in order to engage members and to increase quality and quantity of the services. On the other hand, coworking space operators should become one-stop-shops for start-ups in difficulties, situation caused by the current pandemical situation. Once the trust it's built, operators can expect for the stability of the community and can start to design and develop new services which depend less from physical interactions.

The present research expresses the need of inside platforms where operations can be handled digitally. However, in some cases, the coworking operator and companies both, have firstly to digitize their own managerial processes in order to benefit from the digital services. Shared software applications are recommended to replace offline services from the offer, which cannot be provided anymore or present major risk for contamination. The current situation demonstrates that coworking spaces are not just offices, in the background there are values which argument the commitment of the members. As validated instruments for sharing economy, coworking operators has to consolidate the educational component as value proposition and to align the business model to the digital transformation process, by joining Digital Innovation Hub initiatives. Within the research we found reduced number of examples when a coworking space is acting in a quadruple helix structure. However, the philosophy behind coworking covers more than office spaces with services. A proper coordination, wide network and interdisciplinary approach could strategically measures in order to contribute to regional development and implicitly access to finance which are necessary for coworking businesses as well. In this sense, operators can apply to operational programs in order to get funds for implementing start-up accelerator and granting programs. This kind of programs can ensure financial sustainability for the period while the company develops new services in order to engage members and consolidate the ecosystem around and inside of the coworking space. Despite the fact that the world is expecting to "get back to normal", the demand for digital services will remain actual. Working flows has been changed organically and this change opened new market opportunities (decentralized corporate workers, cross-border workers, others).

Romania is one of those countries where the coworking industry was in emerging stage when the pandemic has occurred. It is also recommended to suggest for policy makers to include coworking spaces in the list of most affected businesses in order to receive covid-19 financial support - non-recoverable grants and advantageous loans for recovery. On the same time, would 
be a strategic move from the part of policy makers to encourage the establishment of new coworking spaces as many companies adopted a decentralized strategy concerning the workflow. Working from home on long term has its social disadvantages, according to the scientific literature. In this context, safe places which increase work productivity are required. Romania also has several unused industrial buildings, which could gain new functionalities in the form of safe coworking places for the post covid-19 period. According to official data, in 2021 there will be considerable grant for new start-ups which also need creative, interactive and safe places to operate. The experience shows that the survival rate of start-up is higher if they make part of a start-up community. In these regards, the recommendations within this paper becomes more relevant and also urgent.

\section{References}

Akhavan, M. (2021). Third places for work: A comprehensive review of the literature on coworking spaces and makerspaces. New workplaces - Location patterns, urban effects and development trajectories. Springer International Publishing, 10.1007/978-3-030-63443-8.

Amir, M.T. (2020). How Coworking Space Impacts Innovation: A Literature Review. Digital Economy for Customer Benefit and Business Fairness, 126-130, DOI:10.1201/ 9781003036173.

Berbegal-Mirabent, J. (2021). What Do We Know about Co-Working Spaces? Trends and Challenges Ahead, Sustainability; 13(3):1416. https://doi.org/10.3390/su13031416.

Bouncken, R.B., Kraus, S. \& Martínez-Pérez, J.F. (2020). Entrepreneurship of an institutional field: the emergence of coworking spaces for digital business models, International Entrepreneurship and Management Journal, 16, 1465-1481, https://doi.org/10.1007/ s11365-020-00689-4.

Bouncken, R.B, Qiu, Y., \& Clauss, T. (2020). Coworking-Space Business Models: MicroEcosystems and Platforms - Insights from China, International Journal of Innovation and Technology Management (IJITM), World Scientific Publishing Co. Pte. Ltd., 17(06), 1-23.

Castilho, M. F., Quandt, C.O. (2017). Collaborative Capability in Coworking Spaces: Convenience Sharing or Community Building?, Technology Innovation Management Review, 7(12), 32-42, http://doi.org/10.22215/timreview/1126.

Hackett, S.M., Dilts, D.M. (2004). A Systematic Review of Business Incubation Research, Journal of Technology Transfer, 29, 55-82.

Maher, S., Tantawi, P., Ragheb, M.A. (2020). Coworking spaces: An exploratory study to identify the challenges and different business models in Egypt, The Business and Management Review, 11( 1), 206-2014

Manzini Ceinar, I., Mariotti, I. (2020). The Effects of Covid-19 on Coworking Spaces: Patterns and Future Trends. New workplaces: Location patterns, urban effects and development trajectories. A worldwide investigation

Osterwalder, A., Pigneur, Y., Clark, T., \& Smith, A. (2010). Business model generation: a handbook for visionaries, game changers, and challengers.

Oswald, K., Zhao, X. (2020). What Is a Sustainable Coworking Space?, Sustainability 2020, 12, 10547, doi:10.3390/su122410547.

Özbozkurt, O. B., (2019). A New Business Model: Co-Working Offices.

Ritter, T., Pedersen, C. L. (2020). Digitization capability and the digitalization of business models in business-to-business firms: Past, present, and future, Industrial Marketing Management, 86, 180-190. 
Păunescu, C., Argatu, R. (2020). Critical functions in ensuring effective business continuity management. Evidence from Romanian companies, Journal of Business Economics and Management, 21(2), 497-520, https://doi.org/10.3846/jbem.2020.12205.

Păunescu, C., Mátyus, E. (2020). Resilience measures to dealing with the COVID-19 pandemic Evidence from Romanian micro and small enterprises, Management \& Marketing, Sciendo, vol. 15(s1), 439-457.

Stangler, D. (2020). Here Are Three Reasons COVID-19 Makes Coworking Spaces Even More Important, Forbes Magazin, https://www.forbes.com/sites/danestangler/2020/04/03/hereare-three-reasons-covid-19-makes-coworking-spaces-even-more-important/?sh=131c9ce $233 \mathrm{ac}$.

Waters-Lyncha, J., and Pottsb, J. (2016). The social economy of coworking spaces: a focal point model of coordination, Review of Social Econonomy.

Amir, M.T. (2020). How Coworking Space Impacts Innovation: A Literature Review, Digital Economy for Customer Benefit and Business Fairness, 126-130, 10.1201/9781003036173.

Yu, R., Burke, M., and Raad, N. (2019). Exploring impact of future flexible working model evolution on urban environment, economy and planning, Journal of Urban Management, 8, Issue 3, 447-457, ISSN 2226-5856, https://doi.org/10.1016/j.jum.2019.05.002.

Coworking Europe provides know-how and connections for all stakeholders, https://coworkingeurope.net/.

How Coworking Impacts Innovation for Startups and Small Businesses in the U.K. (entrepreneur.com), https://www.entrepreneur.com/article/309197.

Incubators without walls (europa.eu), https://ec.europa.eu/employment_social/equal_consolidated/ data/document/integrated\%20business\%20support_incubators\%20without $\% 20$ walls.pdf.

Survey: How Coworking Spaces are Navigating COVID-19, https://www.coworker.com/mag/ survey-how-coworking-spaces-are-navigating-covid-19.

The Coworking model post Covid-19 - The Hamaleh Project, https://thehamalehproject. wordpress.com. 